\title{
Polyolefin Analyses with 10 mm Multinuclear NMR Cryoprobe
}

Zhe Zhou, ${ }^{1 *}$ Rainer Kuemmerle, ${ }^{2 *}$ Nathan Rau, ${ }^{1}$ Donald Eldred, ${ }^{1}$ Aitor Moreno, ${ }^{2}$ Barbara Czarniecki, ${ }^{2}$ Xiaohua Qiu, ${ }^{1}$ Rongjuan Cong, ${ }^{1}$ Anthony P. Gies,${ }^{1}$ Leslie Fan, ${ }^{1}$ Evelyn Auyeung, ${ }^{1}$ Dain B. Beezer, ${ }^{3}$ Huong Dau, ${ }^{3}$ Eva Harth ${ }^{3}$

1. Dow Lake Jackson, TX 77566, USA

2. Bruker Switzerland AG Industriestrasse 26, CH-8117 Fällanden, Switzerland

3. University of Houston, Department of Chemistry, TX 77204, USA

*Corresponding authors:

Zhe Zhou, Ph.D.

Core R\&D Analytical Science: Macromolecular Characterization

Dow

230 Abner Jackson Pkwy, ECB/1B182

Lake Jackson, TX 77566, USA

Tel: 1-979-238-1387 | Fax: 1-979-238-0752 | Email: zzhou@dow.com

Rainer Kuemmerle, Ph.D.

Bruker Switzerland AG, MRS division, Industriestrasse 26

CH-8117 Fällanden, Switzerland

Tel: 41-44-825-9535 | Fax: 41-44-825-9696 | Email: rainer.kuemmerle@bruker.com 


\section{Table of contents:}

Table S1. Sensitivities of different $600 \mathrm{MHz}$ Bruker NMR cryoprobes

Figure S1. DEPT hard $180^{\circ}{ }^{13} \mathrm{C}$ pulse and RINEPT hard $180^{\circ}{ }^{13} \mathrm{C}$ pulse

Figure S2. ${ }^{13} \mathrm{C}$ NMR spectra obtained with different NMR pulse sequences

Figure S3. Bi_Waltz_65_256pl decoupling

Figure S4. ${ }^{13} \mathrm{C}$ NMR spectra of $200 \mathrm{mg}$ of HDPE in $2.8 \mathrm{~g}$ TCE-d2 with $0.025 \mathrm{M} \mathrm{Cr}^{3+}$

Decoupling sequence Bi_Waltz-65_256pl (Bruker format) - page S8

Figure S5. ${ }^{13} \mathrm{C}$ NMR spectra of a PE wax sample. Decoupling effects of some decoupling sequences

Pulse sequence zgig_pisp (Bruker format) - Page S15

Figure S6. Statistic software JMP "means/Anova" and "compare means with student's t test" analyses 
Table S1. Sensitivities of different $600 \mathrm{MHz}$ Bruker NMR cryoprobes.

\begin{tabular}{|c|c|c|c|}
\hline & \multicolumn{3}{|c|}{ Cryoprobe } \\
\hline Sample & $600 \mathrm{MHz} 5 \mathrm{~mm} \mathrm{H} / \mathrm{C}-\mathrm{Si}$ & $600 \mathrm{MHz} 10 \mathrm{~mm} \mathrm{C} / \mathrm{H}$ & $600 \mathrm{MHz} 10 \mathrm{~mm}$ C-Si-N-P/H \\
\hline $0.1 \% \mathrm{~EB}\left({ }^{1} \mathrm{H}\right)$ & 7721 & 7348 & 5600 \\
\hline $\mathrm{ASTM}\left({ }^{13} \mathrm{C}\right)$ & 1155 & 5803 & 5716 \\
\hline $10 \% \mathrm{~EB}\left({ }^{13} \mathrm{C}\right)$ & 1213 & 4932 & 5195 \\
\hline $90 \%$ formamide $\left({ }^{15} \mathrm{~N}\right)$ & & & 345 \\
\hline $0.0485 \mathrm{M} \mathrm{TPP}\left({ }^{31} \mathrm{P}\right)$ & & & 2900 \\
\hline $85 \% \mathrm{HMDSO}\left({ }^{29} \mathrm{Si}\right)$ & 488 & & 2100 \\
\hline
\end{tabular}

Notation used here denotes that the NMR frequencies of nuclei before forward slash symbol are tuned on inner coil and frequencies of nuclei after forward slash symbol are tuned on the outer coil. Table S1 lists signal to noise ratios $(\mathrm{S} / \mathrm{N}$ ) of a selection of $600 \mathrm{MHz}$ Bruker cryoprobes obtained on NMR standard reference samples. The high temperature specification for the used $10 \mathrm{~mm}$ cryoprobes is $135{ }^{\circ} \mathrm{C}$, while the $5 \mathrm{~mm}$ cryoprobe can only reach $80^{\circ} \mathrm{C}$. However, the high temperature specification for all newly designed $5 \mathrm{~mm}$ and $10 \mathrm{~mm}$ Bruker cryoprobes is $150{ }^{\circ} \mathrm{C}$. It can be seen in Table S1 that with $0.1 \%$ ethylbenzene (EB) the $5 \mathrm{~mm} \mathrm{H} / \mathrm{C}$-Si cryoprobe has highest ${ }^{1} \mathrm{H}$ NMR sensitivity. Noting that the ${ }^{1} \mathrm{H}$ is the inner coil for this probe highlights the sensitivity gained through coil proximity, as the $5 \mathrm{~mm}$ NMR probe contains about one quarter of the sample volume relative to the $10 \mathrm{~mm}$ NMR probe. With ASTM ( $40 \%$ p-dioxane in benzene-d6) and $10 \%$ EB samples, ${ }^{13} \mathrm{C}$ NMR sensitivities are similar for the $10 \mathrm{~mm}$ dual $\mathrm{C} / \mathrm{H}$ and $10 \mathrm{~mm}$ multinuclear $\mathrm{C}-\mathrm{Si}-\mathrm{N}-\mathrm{P} / \mathrm{H}$ cryoprobes, and are 4-5 times more sensitive than the $5 \mathrm{~mm} \mathrm{H} / \mathrm{C}-\mathrm{Si}$ cryoprobe. With the $85 \%$ hexamethyldisiloxane (HMDSO) sample, ${ }^{29} \mathrm{Si}$ NMR sensitivity of the $10 \mathrm{~mm} \mathrm{C}$ Si-N-P/H cryoprobe is about 4 times higher than the sensitivity of the $5 \mathrm{~mm} \mathrm{H} / \mathrm{C}-\mathrm{Si}$ cryoprobe. Clearly, design of coil configuration inside of cryoprobe and the diameter of cryoprobe both affect the cryoprobe sensitivity. The $5 \mathrm{~mm} \mathrm{H} / \mathrm{C}$-Si (or $\mathrm{H} / \mathrm{X}$ ) cryoprobe should be selected if ${ }^{1} \mathrm{H}$ NMR is the primary focus and $\mathrm{X}$ 
channel is occasionally needed. For polyolefin characterization, the $10 \mathrm{~mm} \mathrm{C}-\mathrm{Si}-\mathrm{N}-\mathrm{P} / \mathrm{H}$ cryoprobe is clearly the best choice, as it provides 4-5 times higher sensitivity for X-nuclei, which saves 16-25x NMR acquisition time. It is also much easier to prepare polyolefin samples with $10 \mathrm{~mm}$ NMR tubes, especially for high density polyethylene (HDPE). It should be noted that we have previously reported a ${ }^{13} \mathrm{C} \mathrm{NMR}$ S/N of 2677 with an ASTM sample on a $400 \mathrm{MHz} 10 \mathrm{~mm} \mathrm{C/H}$ cryoprobe. ${ }^{1}$ In comparison, its S/N on a 600 MHz $10 \mathrm{~mm} \mathrm{C/H}$ cryoprobe was 5803 (Table S1), which is about 2 times higher when compared with the $400 \mathrm{MHz}$ system, and equates to a 4-fold reduction in acquisition time for the $600 \mathrm{MHz}$ system. This result is close to theoretical value $(600 / 400)^{\wedge}(3 / 2)=1.8$. 


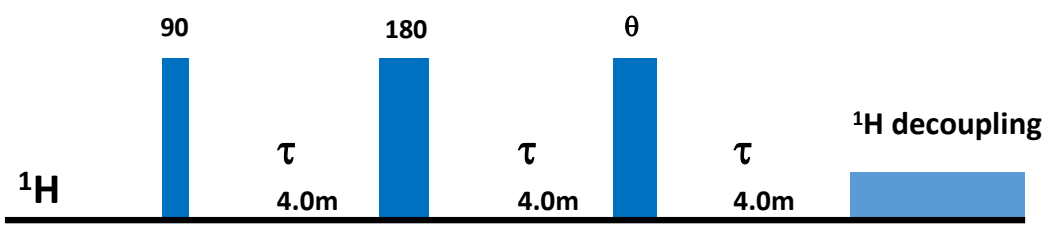

dept
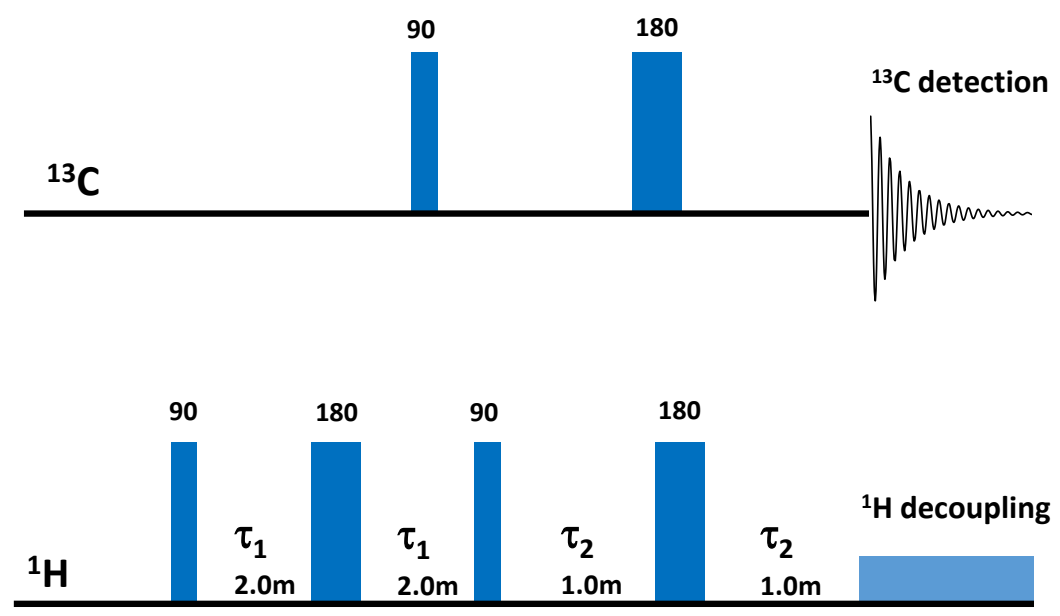

ineptrd

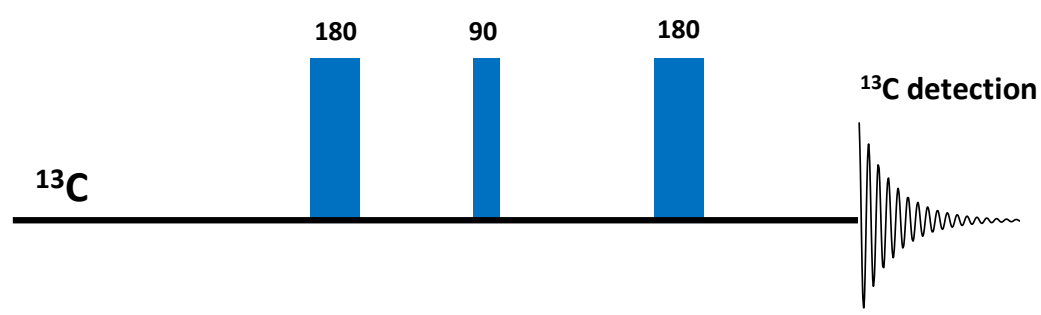

Figure S1. DEPT hard $180^{\circ}{ }^{13} \mathrm{C}$ pulse (DEPTHP, Bruker pulse name "dept") and RINEPT hard $180^{\circ}{ }^{13} \mathrm{C}$ pulse (RINEPTHP, Bruker pulse name "ineptrd"). 


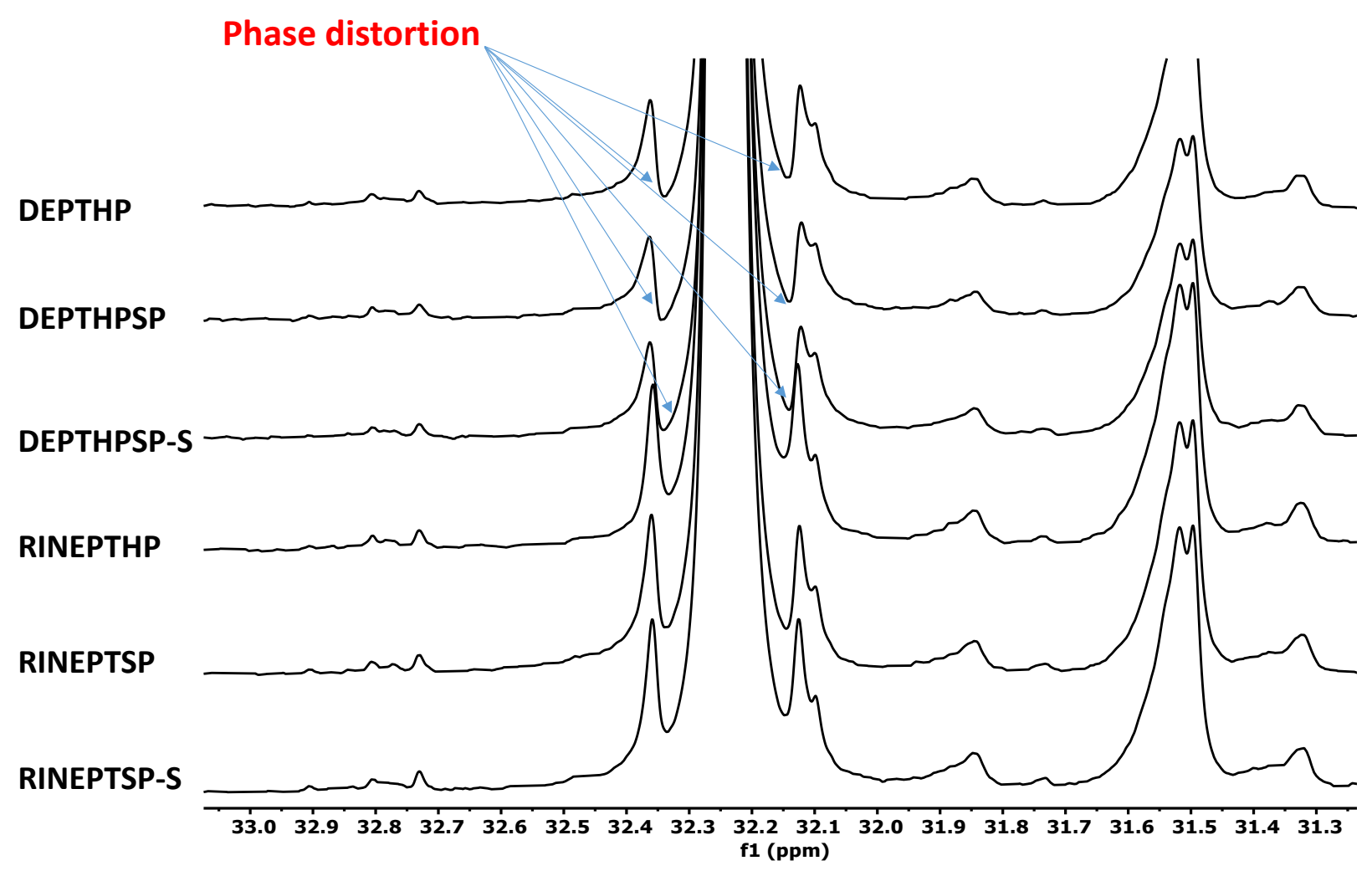

Figure S2. ${ }^{13} \mathrm{C}$ NMR spectra obtained with different NMR pulse sequences. The sample is an ethyleneoctene copolymer in TCE- $d_{2}$ with $0.025 \mathrm{M} \mathrm{Cr}^{3+} .{ }^{13} \mathrm{C}$ transmitter was set at $30.00 \mathrm{ppm}$. Probe sample temperature $120^{\circ} \mathrm{C}$. 

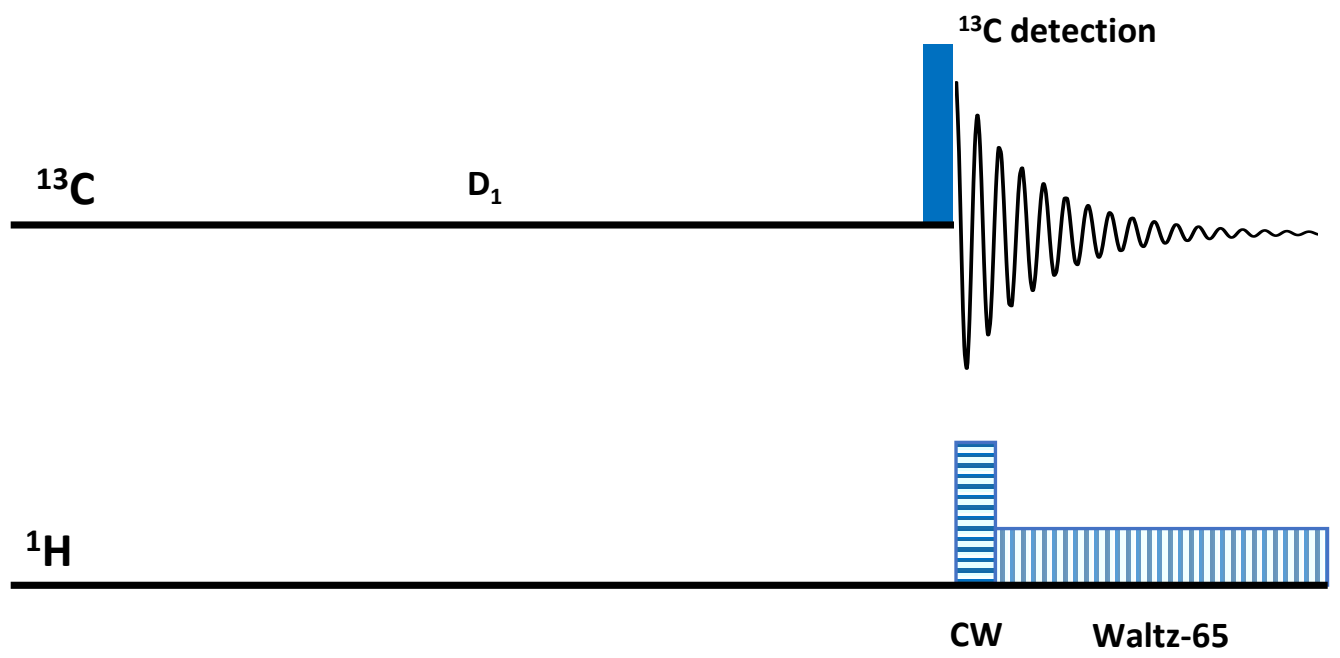

Figure S3. Bi_Waltz_65_256pl decoupling. 256 step bilevel implementation of Waltz-65, D1 = relaxation delay. Decoupling starts upon acquisition of the FID with $\mathrm{CW}$ part, the $\mathrm{CW}$ part increasing from scan to scan until maximum length at 256th scan. Scan 257 is executed with same CW part as the first scan. The power of the applied CW part is $6 \mathrm{~dB}$ higher than the Waltz-65 part to maintain the decoupling bandwidth. 


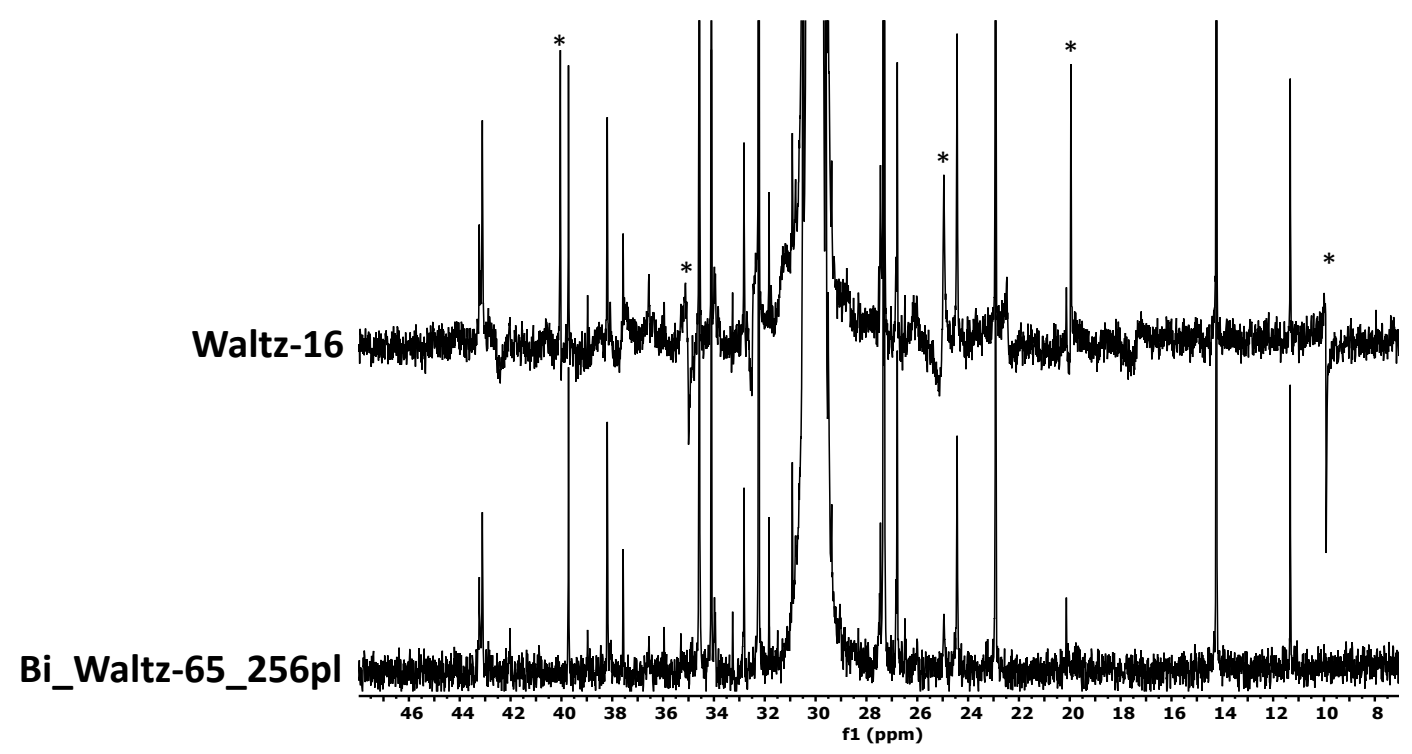

Figure S4. ${ }^{13} \mathrm{C}$ NMR spectra of $200 \mathrm{mg}$ of HDPE in $2.8 \mathrm{~g}$ TCE-d2 with $0.025 \mathrm{M} \mathrm{Cr}^{3+}$. Some decoupling artifacts are marked with *. Decoupling method is shown at left of spectrum. Probe sample temperature $120^{\circ} \mathrm{C}$, NS 1024.

Decoupling sequence Bi_Waltz-65_256pl (Bruker format)

bilev "I31=(nsdone+ds)\%256+1"

1 pcpd*1.84067:0 pl=pl31

lo to 1 times 131

$2 \mathrm{pcpd}^{*} 3: 0 \mathrm{pl}=\mathrm{pl} 30 \quad ; \mathrm{R}$

$\operatorname{pcpd}^{*} 4: 180$

$\operatorname{pcpd}^{*} 2: 0$

pcpd*3:180

pcpd :0

pcpd*2:180

$\operatorname{pcpd}^{*} 4: 0$

pcpd*2:180

pcpd*3:0 


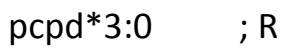

$$
\begin{aligned}
& \text { pcpd*4:180 } \\
& \operatorname{pcpd}^{*} 2: 0 \\
& \text { pcpd*3:180 } \\
& \text { pcpd :0 } \\
& \text { pcpd*2:180 }^{*} \\
& \text { pсpd*4:0 } \\
& \text { pcpd*2:180 } \\
& \text { pcpd*3:0 }
\end{aligned}
$$

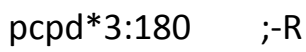

$$
\begin{aligned}
& \text { pcpd*4:0 } \\
& \text { pcpd*2:180 } \\
& \text { pcpd*3:0 } \\
& \text { pcpd :180 } \\
& \text { pcpd*2:0 } \\
& \text { pcpd*4:180 } \\
& \text { pcpd*2:0 } \\
& \text { pcpd*3:180 } \\
& \operatorname{pcpd}^{* 3: 180} ;- \text {; } \\
& \operatorname{pcpd}^{*} 4: 0 \\
& \text { pcpd*2:180 } \\
& \text { pcpd*3:0 } \\
& \text { pcpd :180 } \\
& \text { pcpd*2:0 } \\
& \text { pcpd*4:180 } \\
& \operatorname{pcpd}^{*} 2: 0 \\
& \text { pcpd*3:180 } \\
& \text { pcpd*3:180 ;-R }
\end{aligned}
$$




$$
\begin{aligned}
& \operatorname{pcpd}^{*} 4: 0 \\
& \text { pcpd*2:180 } \\
& \operatorname{pcpd}^{*} 3: 0 \\
& \text { pcpd :180 } \\
& \text { pcpd*2:0 } \\
& \text { pcpd }^{*} 4: 180 \\
& \text { pcpd*2:0 } \\
& \text { pcpd*3:180 } \\
& \text { pcpd*3:0 ; R } \\
& \text { pcpd*4:180 } \\
& \operatorname{pcpd}^{*} 2: 0 \\
& \text { pcpd*3:180 } \\
& \text { pcpd :0 } \\
& \operatorname{pcpd}^{*} 2: 180 \\
& \operatorname{pcpd}^{*} 4: 0 \\
& \operatorname{pcpd}^{*} 2: 180 \\
& \text { pcpd*3:0 } \\
& \operatorname{pcpd}^{*} 3: 0 \quad ; R \\
& \text { pcpd*4:180 } \\
& \operatorname{pcpd}^{*} 2: 0 \\
& \text { pcpd*3:180 } \\
& \text { pcpd :0 } \\
& \text { pcpd*2:180 }^{*} \\
& \text { pcpd*4:0 } \\
& \text { pcpd*2:180 } \\
& \operatorname{pcpd}^{*} 3: 0 \\
& \operatorname{pcpd}^{*} 3: 180 \quad ;-R \\
& \text { pcpd*4:0 }
\end{aligned}
$$




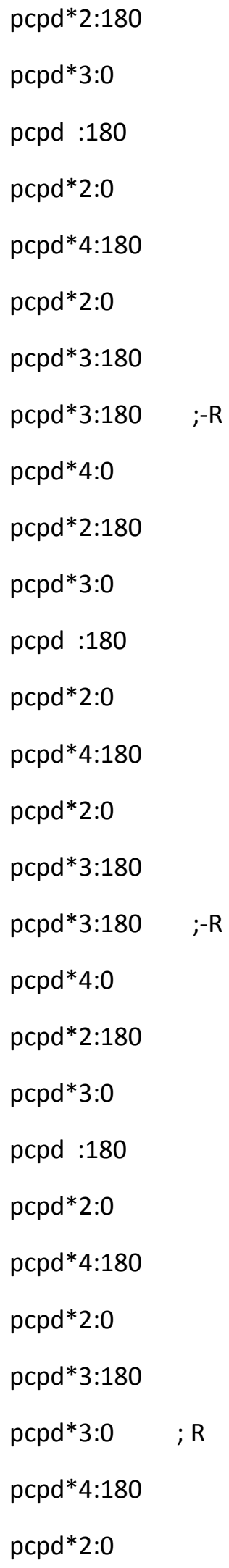




$$
\begin{aligned}
& \operatorname{pcpd}^{* 3: 180} \\
& \text { pcpd :0 } \\
& \text { pcpd*2:180 } \\
& \text { pcpd*4:0 } \\
& \text { pcpd*2:180 } \\
& \operatorname{pcpd}^{*} 3: 0 \\
& \operatorname{pcpd}^{* 3: 0 \quad ; R} \\
& \text { pcpd*4:180 } \\
& \operatorname{pcpd}^{*} 2: 0 \\
& \text { pcpd*3:180 } \\
& \text { pcpd :0 } \\
& \text { pcpd*2:180 } \\
& \text { pcpd*4:0 } \\
& \operatorname{pcpd}^{*} 2: 180 \\
& \text { pcpd*3:0 } \\
& \text { pcpd*3:0 ; R } \\
& \operatorname{pcpd}^{*} 4: 180 \\
& \text { pcpd*2:0 } \\
& \operatorname{pcpd}^{*} 3: 180 \\
& \text { pcpd :0 } \\
& \text { pcpd*2:180 } \\
& \text { pсpd*4:0 } \\
& \text { pcpd*2:180 } \\
& \text { pcpd*3:0 } \\
& \operatorname{pcpd}^{*} 3: 180 \quad ;-R \\
& \operatorname{pcpd}^{*} 4: 0 \\
& \text { pcpd*2:180 } \\
& \text { pcpd*3:0 }
\end{aligned}
$$




$$
\begin{aligned}
& \text { pcpd :180 } \\
& \text { pcpd*2:0 } \\
& \text { pcpd*4:180 } \\
& \operatorname{pcpd}^{*} 2: 0 \\
& \text { pсpd*3:180 }
\end{aligned}
$$

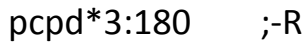

$$
\begin{aligned}
& \text { pcpd*4:0 } \\
& \text { pcpd*2:180 } \\
& \text { pcpd*3:0 } \\
& \text { pcpd :180 } \\
& \text { pcpd*2:0 } \\
& \text { pcpd*4:180 } \\
& \operatorname{pcpd}^{*} 2: 0 \\
& \text { pcpd*3:180 } \\
& \text { pcpd*3:0 ; R } \\
& \operatorname{pcpd}^{*} 4: 180 \\
& \operatorname{pcpd}^{*} 2: 0 \\
& \text { pcpd*3:180 } \\
& \text { pcpd :0 } \\
& \text { pcpd*2:180 } \\
& \text { pcpd*4:0 } \\
& \text { pcpd*2:180 } \\
& \text { pcpd*3:0 } \\
& \text { pcpd :0 } \\
& \text { jump to } 2
\end{aligned}
$$




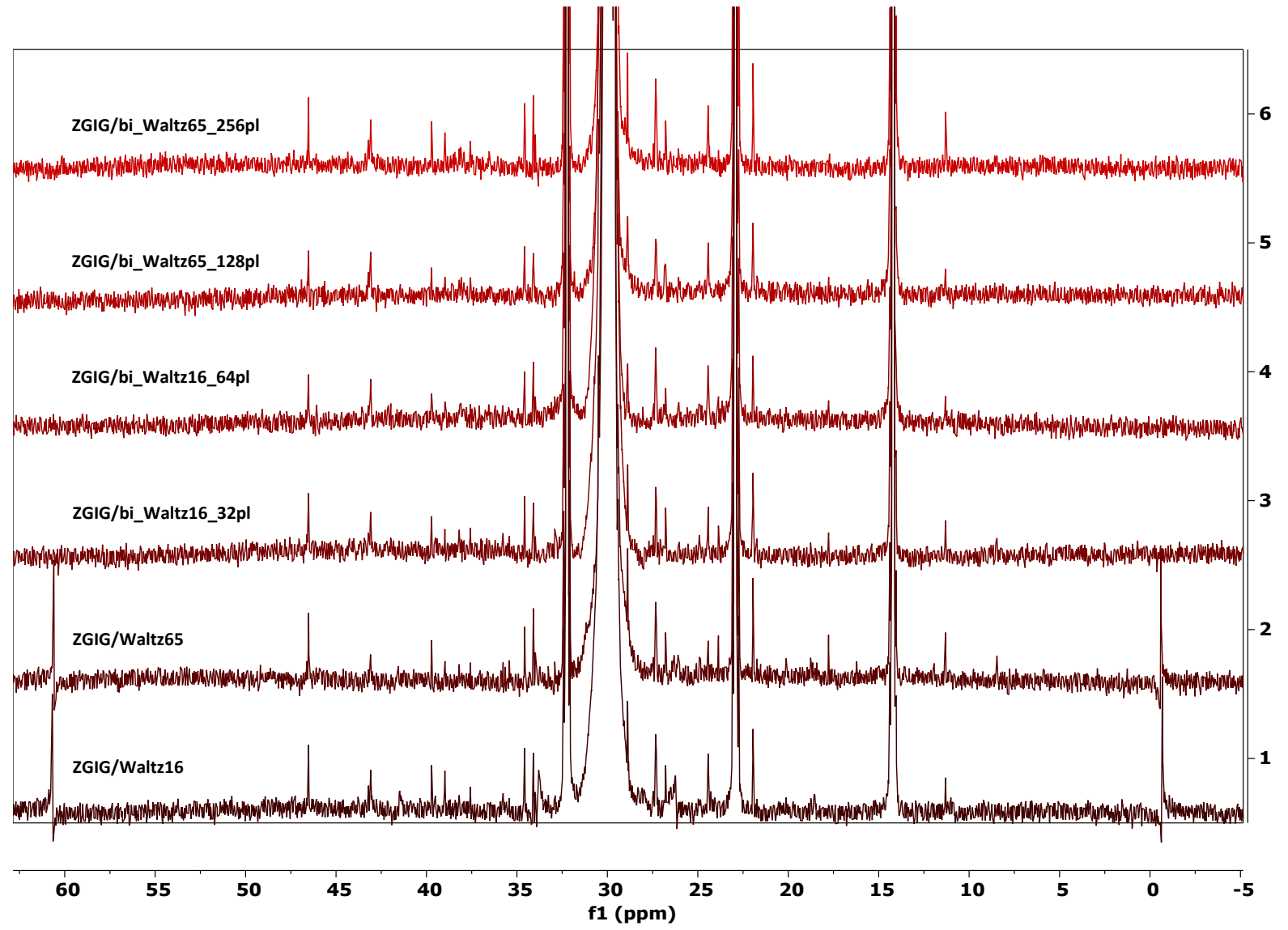

Figure S5. ${ }^{13} \mathrm{C}$ NMR spectra of a PE wax sample. Decoupling effects of some decoupling sequences are shown. 


\section{Pulse sequence zgig_pisp (Bruker format)}

;zgig_pisp

;avance-version

;1D sequence

;a weak 2-5\% gradient may also be added after the pi pulse

\section{;\$OWNER=nmr}

\#include<Avance.incl $>$

\#include<Grad.incl $>$

"d14 = 1.0m"

"acqt0=-p1*2/3.1416"

"d11=30m"

1 ze

d11 pl1:f1 pl12:f2

$230 \mathrm{~m}$ do:f2

d1

$$
\begin{aligned}
& \text { "I9=2*((I1)\%2)" } \\
& 1 \text { iu1 } \\
& \text { if "I9==0" goto lab3 } \\
& \text { (p18:sp8 ph1):f1 } \\
& \text { d14 }
\end{aligned}
$$

lab3, $4 u$

d14 pl1:f1 pl12:f2

$$
\text { p1 ph2 }
$$$$
\text { go=2 ph31 cpd2:f2 }
$$

$30 \mathrm{~m}$ do:f2 $\mathrm{mc} \# 0$ to $2 \mathrm{FO}(\mathrm{zd})$

exit 
ph1 $=0$

ph2=0 0112233

ph31=2 0310213

;pl1 : f1 channel-power level for pulse (default)

;p1 : f1 channel-high power pulse (90deg)

;pl12: f2 channel - power level for CPD/BB decoupling

;sp8: f1 channel - shaped pulse (180degree inversion)

;spnam2: Crp80,0.5,20.1

;d1 : relaxation delay; $1-5 * \mathrm{~T} 1$

;d11: delay for disk I/O (30ms)

;d14 : pi delay

;NS : $1^{*} n$, total number of scans: NS*TDO

;cpd2: decoupling according to sequence defined by cpdprg2

;pcpd2: $f 2$ channel - 90 degree pulse for decoupling sequence 


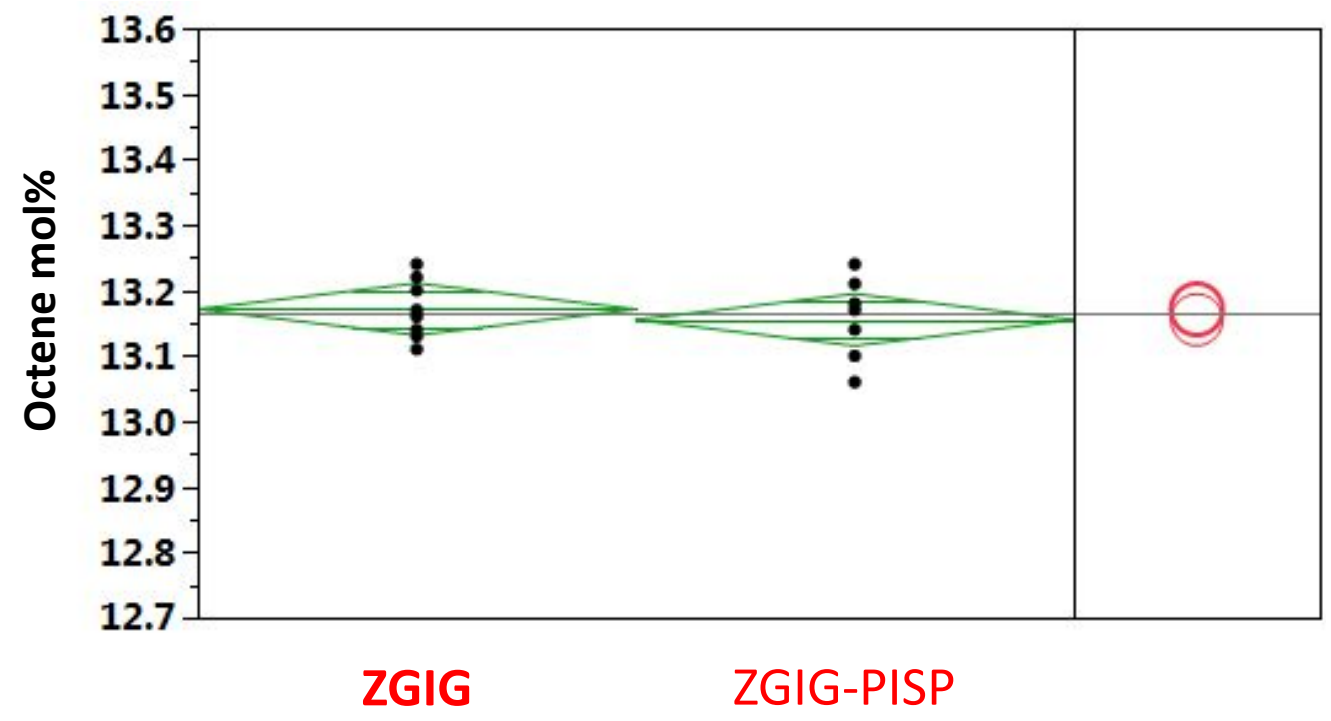

Figure S6. Statistic software JMP “means/Anova" and "compare means with student's t test" analyses of 8 octene mol\% contents from conventional quantitative zgig pulse sequence and 8 octene contents from new zgig_pisp pulse sequence.

The green diamond from "means/Anova" shows $95 \%$ confidence intervals for each mean. The $p$-value (Prob > F) from "means/Anova" is used to evaluate the validity of the null hypothesis that all the means are the same. Exceeding the null hypothesis threshold value of 0.05 , measured here at 0.5432 , leads to the conclusion that the means are indistinguishable. The red cycle at right is from "compare means with student's t test", the cycle corresponding to zgig_pisp pulse sequence turned red after clicking the cycle corresponding to zgig pulse sequence.

${ }^{1}$ Zhou, Z.; Kuemmerle, R.; Stevens, J.; Redwine, D.; He, Y.; Qiu, X.; Cong, R.; Klosin, J.; Montanez, N.; Roof, G., $13 C$ NMR of polyolefins with a new high temperature $10 \mathrm{~mm}$ cryoprobe. J. Magn. Reson. 2009, 200, 328-333. 